\title{
Forecasting animal migration using SARIMAX: an efficient means of reducing silver eel mortality caused by turbines
}

\author{
T. Trancart ${ }^{1, *}$, A. Acou $^{1}$, E. De Oliveira ${ }^{2}$, E. Feunteun ${ }^{1}$ \\ ${ }^{1}$ Muséum National d'Histoire Naturelle, 38 rue du port blanc, 35800 Dinard, France \\ ${ }^{2}$ EDF-R\&D, LNHE 6 quai Watier, 78400 Chatou, France
}

\begin{abstract}
Hydroelectric power plants are often considered a major cause of mortality for migratory fish. The endangered status of European eels Anguilla anguilla forces managers to make efforts to reduce this mortality. Among the mitigation measures used, turbine shutdowns appear to be an efficient method, but they involve a substantial financial loss for hydropower producers. To optimise the use of turbine shutdowns, the present study aimed to provide a precise but simple forecast of the migration peaks of migrant silver eels. We first developed a model to forecast silver eel migration using SARIMAX models and real biological data of silver eel migration from 2 fishing sites in Brittany (north-western France). This model combines exogenous covariates and past biological data to forecast future migrations. We then evaluated this model with several years of biological data from the same trap sites, based on the decision criterion that turbines should be shut down when the number of silver eels forecasted by our model represents $>10 \%$ of the mean annual number of migrants. This model would have served to save 90 and $70 \%$ of eels on the Oir and Scorff Rivers, respectively, with only 3.3 to 5.6 turbine shutdowns per year on average. Initial shutdowns would have lasted $1 \mathrm{wk}$, but this study also showed that the duration of turbine shutdowns could be reduced to $2 \mathrm{~d}$ without a significant decrease in efficiency. SARIMAX models reduce the influence of exogenous factors in forecasting outcomes, these being the most variable factors in the current context of climate change. This model appears to be a powerful tool for ecological forecasting of endangered species in the context of global warming.
\end{abstract}

KEY WORDS: Forecasting models $\cdot$ Migratory species $\cdot$ Mitigation $\cdot$ Management $\cdot$ Anguillid eels Resale or republication not permitted without written consent of the publisher

\section{INTRODUCTION}

Migration is a fascinating behaviour, and is seen in a large range of animal taxa. Each year, many migrant species use ecological pathways to reach either spawning grounds or growth habitats. Anthropogenic pressures have greatly reduced the connectivity of some of these pathways, thus considerably increasing the risk of injuries, and even mortalities, among migrant individuals. Migrations can also cause disturbances to human activities, such as air traffic or farming. Migration forecasting thus appears to be a crucial aspect of migratory species management in the inter- ests of both animals and humans. Several studies have attempted to provide precise forecasts of migration in order to limit the possible effects of animals on human activities or to limit animal mortality during migration. For example, to reduce collisions between birds and aircraft, Van Belle et al. (2007) created a regression model forecasting migration intensities of birds using meteorological data. The migration of the large ungulate Bison bison can also be predicted using a single unifying model (Geremia et al. 2011). The forecast of monsoonal rains can be used to simulate the famous annual breeding migration of red crabs on Christmas Island (Adamczewska \& Morris 2001). Several studies, 
such as that by Klueken et al. (2009), have shown the possibility of forecasting the migration of pest insects using several exogenous predictor variables.

Migration mechanisms are highly elaborate, and proximate factors in migration are both exogenous (environmental cues that can trigger or inhibit migrations) and endogenous (under physiological and hormonal control). Migration is defined as a persistent, straightened out movement not distracted by resources (Dingle 1996), suggesting that migration is a highly sensitive stage in an animal's life history.

This is particularly true of diadromous fishes, which regularly migrate between freshwater and marine environments at a specific stage of their life cycle. Of these migratory fish, catadromous species share the particular strategy of spending most of their life cycle in freshwater and migrating towards the sea for the purpose of breeding (McDowall 1988). This breeding migration between freshwater and saltwater implies a passage through narrow ecological pathways, called corridors, where anthropogenic and ecological pressures can be very strong. Hydropower facilities, which use turbines, represent one such pressure. Because hydropower is a sustainable source of energy, the number of such facilities is expanding. During the life cycle of the catadromous European eels Anguilla anguilla, the silver eel stage, which corresponds to the seaward migration phase (Durif et al. 2005), is particularly susceptible to mortality from turbines (Larinier \& Travade 2002) because of their elongated body shape.

Several studies have shown the negative impacts of hydropower on adult silver eels, with mortalities ranging from 5 to $100 \%$ in the case of old turbines (see review by McCarthy et al. 2008). Because European eels are classified as an Endangered species, conservation measures have been recommended by the European Union. Currently, the European Union Directive 1100/2007 of 18 September 2007 recommends that mitigation measures be introduced by hydropower facilities. One option is to prevent the migrants from passing by turbines, by orienting them to a safe route using controlled spillage (Watene \& Boubee 2005), eel-suitable downstream bypasses (Gosset et al. 2005) and mechanical and behavioural deflection technologies (Russon et al. 2010). A second option is to develop fish-friendly turbines to limit mortality (Hecker \& Cook 2005). Unfortunately, neither method has yet provided an efficient solution to eel mortality.

Until now, the best way to reduce mortality has been to stop the turbines during the migration period. However, shutting down turbines during the whole migration period, which can last 6 mo for European eels, is not an economically acceptable option. Thus, there is a real need to forecast the migration events (when migration activity is at a maximum) to (1) reduce turbine mortality and (2) limit the financial loss.

Forecasting models using covariates have been developed for eels (Vollestad et al. 1986, Haro 2003, Durif \& Elie 2008). These models forecast migrations using linear regression between eel strengths and exogenous factors. However, seasonal effects of exogenous factors induce autocorrelation problems, since data independence, one of the fundamental requirements of a regression model, is not respected. Using a differentiation process with season as order, SARIMAX was designed to remove seasonal autocorrelation.

Another problem is that linear models are only based on exogenous factors. In the current context of global warming, exogenous factors will be strongly modified in the coming years, and it is not clear how silver eel populations will adapt to these modifications. Other models that include biological data from previous years may be more adaptable in this context. SARIMAX models are fitted with time series data and have been widely used in econometrics (Mills 1990), but rarely in ecology (Tankersley et al. 1993, Craine et al. 2003).

To develop effective management tools to reduce mortality through turbines or hydraulic devices and by fisheries, we need to be able to better forecast the downstream migration of silver eels. This study aimed to create a new model for forecasting silver eel downstream migration using simple exogenous factors and SARIMAX models specifically developed for the forecasting of time series. In a forecasting approach, the reduction in exogenous factors is a crucial point, because these factors are usually not available or are difficult to obtain in advance (i.e. enough time before the forecast). We thus selected the most parsimonious model, i.e. the one which used the fewest exogenous factors. To test the forecasting approach and the model developed, we simulated mitigation measures (turbine shutdowns) to quantify the benefit to species, if this model were to be applied.

\section{MATERIALS AND METHODS}

\section{Study sites and data acquisition}

This study is based on data from 2 small rivers in northwestern France (Fig. 1), the Oir and Scorff Rivers. The small Oir watershed covers $86 \mathrm{~km}^{2}$ and is 


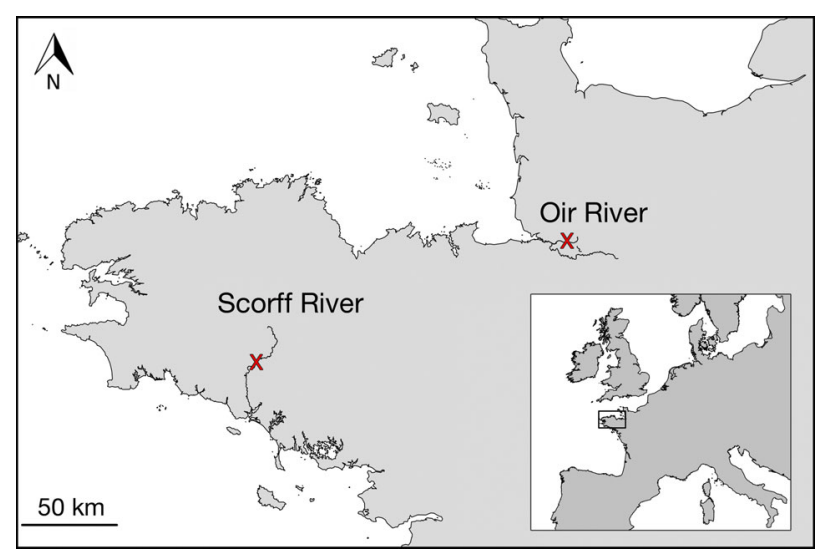

Fig. 1. Study sites on the Oir and Scorff Rivers, northwestern France. Crosses: sampling sites

$21 \mathrm{~km}$ in overall length. The Scorff River watershed has an area of $490 \mathrm{~km}^{2}$ and an overall length of $78 \mathrm{~km}$. Despite their small sizes, these rivers have a wide range of habitats varying from high velocity trout zones to lentic bream zones. There is no significant dam (or associated turbine) obstructing downstream migration in these rivers. However, the data sets were used to model the relations between environmental triggers and migration as a theoretical framework for management purposes. Migrant silver eels were collected using traps for migrant eels located in the lower parts of the rivers. No tests were undertaken to quantify capture rates on these rivers, but the locations of traps in the main stems of the rivers and the trap design suggest very high capture rates of silver eels. Traps were checked daily during the eel migration period in order to prevent eel mortality. Eel stages were observed in order to consider only silver eels according to Acou et al. (2005), and eels were immediately released into the water. All samples were collected between January 2001 and December 2011 in the Oir River and between January 1999 and August 2011 in the Scorff River.

Climatic data were reported daily from 1999 to 2012 for the 2 trap locations. Data were kindly provided by Meteo France. The values for 3 main parameters were collected: mean temperature $\left({ }^{\circ} \mathrm{C}\right)$, rainfall $(\mathrm{mm})$ and atmospheric pressure $(\mathrm{hPa})$.

\section{Forecasting migration model}

The forecasting model developed in this study (forecasting migration model [FMM]) was based on seasonal auto-regressive integrated moving average (SARIMA) models. SARIMA models are the most effi- cient class of models for forecasting a non-stationary time series, which can be made stationary by transformations such as differencing (Mills 1990). A SARIMA $(p, d, q)(P, D, Q)[s]$ model has the following components:

- $\mathrm{p}$ and $\mathrm{P}$, the autoregressive and seasonal autoregressive orders, respectively

- $\mathrm{d}$ and $\mathrm{D}$, the degree of non-seasonal and seasonal differencing, respectively

- $\mathrm{q}$ and $\mathrm{Q}$, the moving average and seasonal moving average orders, respectively

- $\mathrm{s}$, the length of the seasonal period.

A stationary time series is a time series the variance and mean of which do not change over time. This definition implies that series that have a non-stationary mean (trend) or a periodic or seasonal component are non-stationary time series. The SARIMA differencing process enables non-stationary time series to be analysed by stabilising the time series mean.

The FMM was also based on SARIMAX models. SARIMAX models represent an extension of SARIMA modelling that attempts to forecast the number and timing of silver eel migrations using (1) past migration data (the SARIMA part) and (2) climatic factors (the exogenous part). A bibliographical review showed many factors that can affect silver eel migration (see Table 1 for list). The predictors tested in

Table 1. Exogenous factors that influence downstream migration of silver eels Anguilla anguilla

\begin{tabular}{|c|c|}
\hline Factors & Sources \\
\hline Rainfall & $\begin{array}{l}\text { Burnet (1969), Todd (1981), Acou et al. } \\
(2000,2008), \text { Boubee et al. (2001), } \\
\text { Okamura et al. (2002), Durif et al. (2003), } \\
\text { Haro et al. (2003) }\end{array}$ \\
\hline River flow & $\begin{array}{l}\text { Lowe (1952), Todd (1981), Haraldstad et al. } \\
\text { (1985), Vollestad et al. (1986), Moriarty } \\
\text { (1989), Hadderingh et al. (1999), Acou et } \\
\text { al. (2000, 2008), Boubee et al. (2001), } \\
\text { Behrmann-Godel \& Eckmann (2003), } \\
\text { Cullen \& McCarthy (2003), Durif et al. } \\
\text { (2003), Miyai et al. (2004), Gosset et al. } \\
\text { (2005), Bruijs et al. (2009) }\end{array}$ \\
\hline Temperature & $\begin{array}{l}\text { Lowe (1952), Vollestad et al. (1986), } \\
\text { Okamura et al. (2002), Miyai et al. (2004) }\end{array}$ \\
\hline Lunar phase & $\begin{array}{l}\text { Lowe (1952), Moriarty (1989), Poole \& } \\
\text { Reynolds (1990), Okamura et al. (2002), } \\
\text { Behrmann-Godel \& Eckmann (2003), } \\
\text { Miyai et al. (2004) }\end{array}$ \\
\hline Wind & Moriarty (1989), Cullen \& McCarthy (2003) \\
\hline $\begin{array}{l}\text { Atmospheric } \\
\text { pressure }\end{array}$ & $\begin{array}{l}\text { Burnet (1969), Okamura et al. (2002), } \\
\text { Cullen \& McCarthy (2003), Acou et al. } \\
(2008)\end{array}$ \\
\hline Turbidity & Durif et al. (2003) \\
\hline Conductivity & Durif et al. (2003) \\
\hline
\end{tabular}


the present study were the most cited and easily accessible: rainfall, atmospheric pressure and water temperature. Although described as one of the most important factors controlling silver eel downstream migration in small rivers (Acou et al. 2008, 2011), water flow was not used in the present study, because this information is lacking for many rivers and because daily data on rainfall, which is good proxy for flow, is easily available.

The FMM was composed of 3 different submodels. The first sub-model was a SARIMA without covariates. This model was based on previous migration data and determined the phenological windows for migration. This model was assigned binary outcomes, where 0 represented periods with no occurrence of migration and 1 represented periods with some migration.

The second sub-model was again a SARIMA, but using annual data. The aim of this model was to forecast the potential number of migrant fish for each year. This model was built to limit the number of over-predictions. Each year, the number of migrants is finite, and when most fish have already migrated, the probability of a new migration is very low. This model was used to create a weekly 'achievement variable' which corresponded to the proportion of fish that had already migrated compared to the total number expected to migrate each year.

The third sub-model was a null SARIMAX model developed to calculate the relative deviance explained by covariates. Linear regressions were calculated between the number of migrants and covariates (rainfall, pressure and temperature). Correlations between covariates were preliminarily computed, and variables with $>50 \%$ correlation with other previous variables were not used in models. Homoscedasticity and application conditions of linear models were checked. This model was performed only for periods that had a non-null probability of migration according to the first model.

The final model combined the 3 previous sub-models to generate the number of fish expected to migrate each week.

For all sub-models, the order components $(\mathrm{p}, \mathrm{d}, \mathrm{q}$ and $P, D, Q)$ were selected by minimisation of the Bayesian information criterion (BIC) statistic (Zhu et al. 2009). These criteria were also used to choose the most effective combinations of exogenous factors.

The seasonal component of fish migration (used in the 3 sub-models) was calculated by short-time Fourier transform analysis (STFT). STFT is based on the usual Fourier transform performed on an appropriate sliding window of time (Allen \& Rabiner 1977).
The size of the sliding window was adjusted to 3 yr to highlight annually rhythmic behaviours and to fit with the Nyquist frequency (Nyquist 1928). Before STFT, linear least-squares trends were removed; and high-frequency noise and non-linear trends were removed using a passband Butterworth filter, as recommended by Dowse \& Ringo (1989). STFT shows the strength of the variations (energy) of a time series at each oscillation frequency. In other words, it decomposes the variance of a time series into its periodicities. STFT results are presented in 2-dimensional (2D) periodograms, where the stronger and more powerful periods are represented in red and the weaker in yellow (see Fig. 2).

Time series analysis by FMM was performed on the weekly number of silver eels. Daily forecasts were impossible to use for statistical reasons (day $n$ in year $y$ is not linked with day $n$ in years $y-1$ and $y+1$ ), while a monthly forecast would not be accurate enough for good species management. This weekly analysis frequency was a trade-off between the accuracy of timing predictions and the robustness of the model.

The use of past migration data in our model requires a long period of catch data. With a seasonal periodicity, FMM needs 4 yr of catch data to run. This period is called the 'learning process period'.

\section{Application to turbine management}

To test FMM, we simulated the effects of mitigation measures (turbine shutdowns) to reduce turbine mortality, i.e. the improvement in silver eel survival if this model was to be applied. We used the highest eel turbine mortality of $100 \%$ proposed by (McCarthy et al. 2008). The improvement in silver eel survival was measured as the percentage of fish which would not have been killed by turbines if the model had been applied.

The time series were divided into 2 parts each. The first part was the learning process period. In the second part, models were tested weekly using model data from the previous period (the learning process period) and the forecasting of exogenous covariates for the week. The outcomes of the FMM model were then graphically compared to observed data (plot of predicted and observed migrant silver eels).

In the context of turbine management, managers need rules to decide when they have to shut down the turbines. We simply used a detection peak threshold. This threshold was set to $10 \%$ of the 
mean annual number of migrant silver eels. The decision criterion used was 'when the annual number of silver eels forecasted by FMM is $>10 \%$ of the mean annual number of migrants, the turbines should be shut down'. The efficiency of FMM was calculated by computing the number of eels not killed by turbines using this decision criterion to the total number of migrant silver eels.

\section{RESULTS \\ Seasonal behaviour in downstream migration}

The first step in developing the SARIMAX model was to accurately highlight the seasonal components of the time series. For the Oir and Scorff Rivers (Fig. 2), analysis by STFT showed the main periodicity to be about 52 wk. This periodicity appeared stable for the 2 time series. Thus, a 52 wk period was chosen, and time series data (eels and exogenous factors) were summed for each week.

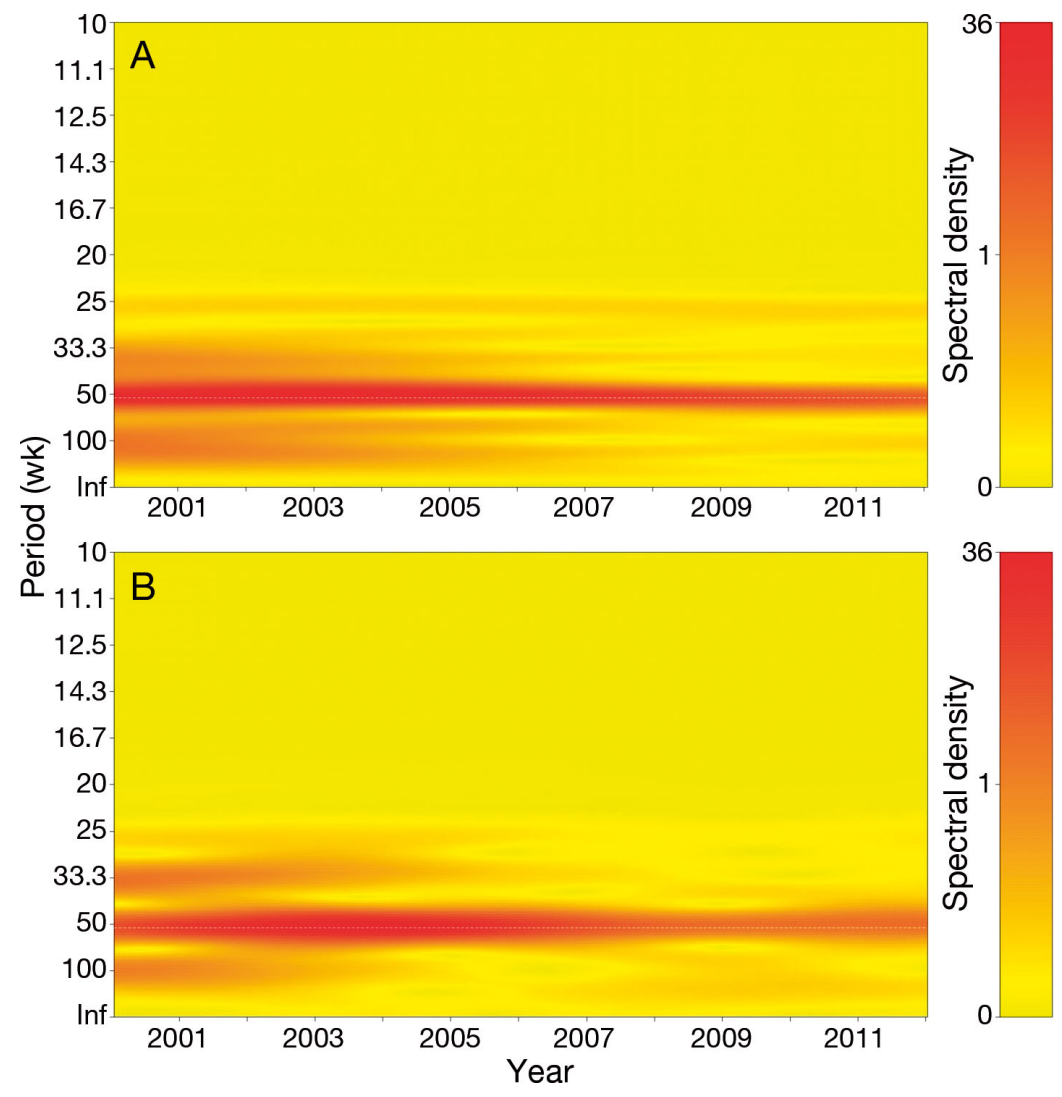

Fig. 2. Short-term Fourier transform analysis results for silver eel catches in the (A) Oir River and (B) Scorff River, from 2000 to 2012. The colour level is a function of the spectral density of periods present in the time series, with red for high and yellow for low density. Inf: infinity

\section{Most effective models}

Using the BIC, the most parsimonious model for both study sites was the FMM, which used only the total weekly rainfall and the achievement vari- able computed by the second sub-model. Adding other covariates (pressure and/or temperature) did not significantly improve the models (Table 2). The selected model did not reveal any major violation of the modelling assumptions (i.e. residual normality, homoscedasticity).
Table 2. Bayesian information criterion (BIC) results for all tested models for the Oir and Scorff rivers in northwestern France. Rainfall is the daily quantity of rain, (in mm), at the trap sites. Pressure is the daily atmospheric pressure at the trap sites $(\mathrm{hPa})$. Temperature is the daily air temperature at the trap sites $\left({ }^{\circ} \mathrm{C}\right)$. Achievement is the number of silver eels counted in week $W$ over the annual number of expected silver eels $(\%)$. Bold print indicates the selected model

\begin{tabular}{|lcc|}
\hline Covariates & Oir River & Scorff River \\
\hline Eel data, rainfall & 1051.25 & 1022.00 \\
Eel data, rainfall, achievement & $\mathbf{9 8 7 . 1 9}$ & $\mathbf{1 0 2 1 . 5 4}$ \\
Eel data, rainfall, achievement, pressure & 993.11 & 1032.95 \\
Eel data, rainfall, pressure & 1057.33 & 1030.55 \\
Eel data, rainfall, temperature & 1057.42 & 1033.86 \\
Eel data, rainfall, achievement, temperature & 993.36 & 1030.32 \\
\hline
\end{tabular}

\section{Model outcomes}

On the Oir River, FMM was performed from 2000 to 2012. The period 2000 to 2005 was the learning process period. Weekly forecasting was performed for the 2005 to 2012 period. For each week $W_{t}$ from 2005 to 2012, the number of migrating silver eels was forecasted using only the rainfall data of $W_{t+1}$ and the achievement variable (number of silver eels counted in week $W$ over the annual number of expected silver eels). Results are presented in Fig. 3 and Table 3. Due to high annual variability, the quantitative forecasting was not very accurate, 
Table 3. Evaluation of the forecasting migration model (FMM) for the Oir and Scorff Rivers using a threshold of $10 \%$ of the mean annual number of migrants

\begin{tabular}{|lccc|}
\hline Timing approach & $\%$ & Quantitative approach \\
\hline Oir River & & & \\
Weeks with forecasted peak/Weeks with observed peak & 90.9 & Fish migrating during weeks with & 89.9 \\
Weeks without forecasted peak/Weeks without observed peak & 92.7 & forecasted peaks/Total fish migrating & 10.1 \\
Weeks with forecasted peak/Weeks without observed peak & 9.1 & Fish migrating during weeks without \\
Weeks without forecasted peak/Weeks with observed peak & 7.3 & forecasted peaks/Total fish migrating \\
Scorff River & 42.9 & Fish migrating during weeks with \\
Weeks with forecasted peak/Weeks with observed peak & 96.5 & forecasted peaks/Total fish migrating & 70.5 \\
Weeks without forecasted peak/Weeks without observed peak & 57.1 & Fish migrating during weeks without & 29.5 \\
Weeks with forecasted peak/Weeks without observed peak & 3.5 & forecasted peaks/Total fish migrating \\
Weeks without forecasted peak/Weeks with observed peak & & &
\end{tabular}

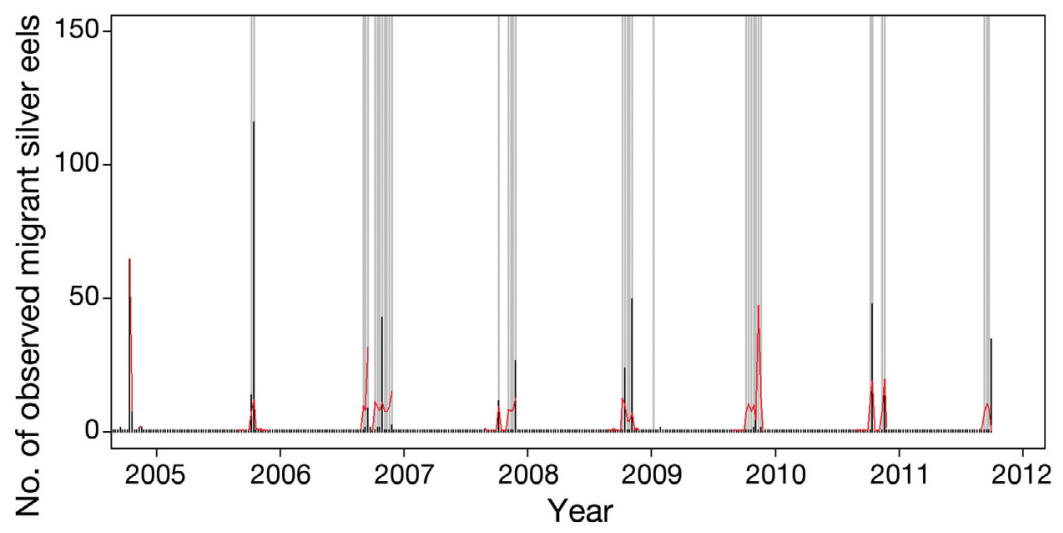

Fig. 3. Forecasting using a forecasting migration model for the Oir River from 2005 to 2012. Red lines: forecasted number of silver eels; black lines: observed number of silver eels, with short black lines on $x$-axis indicating 0 fish; grey bars: periods when turbines would have been shut down based on a threshold of $10 \%$ of the mean annual number of migrants (thickness of bars indicates duration of shutdown)

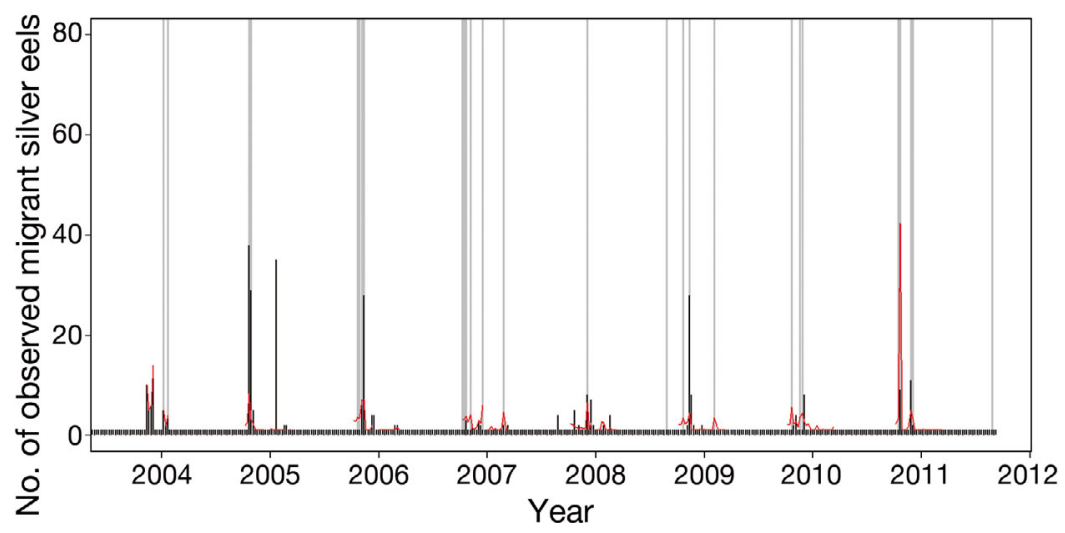

Fig. 4. Forecasting using a forecasting migration model for the Scorff River from 2004 to 2011. Red lines: forecasted number of silver eels; black lines: observed number of silver eels, with short black lines on $x$-axis indicating 0 fish; grey bars: periods when turbines would have been shut down based on a threshold of $10 \%$ of the mean annual number of migrants (thickness of bars indicates duration of shutdown) i.e. values were either underestimated (season 2005 to 2006 for the Oir River) or overestimated (2009 to 2010 for the Oir River). Conversely, the timing forecasting was very accurate, because all the major events (peaks, regardless of the number of individuals) were forecasted at the correct time. For instance, $91 \%$ of weeks with observed peaks were correctly forecasted for the Oir River (see Table 3 for details); and about $93 \%$ of weeks without a peak were correctly forecasted (Table 3).

On the Scorff River, FMM was used from 1999 to 2012. The period 1999 to 2005 was the learning process period. Results are presented in Fig. 4 and Table 3. Similar to that in the Oir River, annual variability was very high, ranging from $<10$ eels in 2010 to 150 in 2004. Thus, quantitative forecasting was not very accurate. On the other hand, the timing forecast was very accurate, because all of the major events (peaks, regardless of the number of individuals), except one, were correctly forecast (see Table 3 for details).

\section{Application to turbine management}

FMM was evaluated as a management tool (decision criterion) for the Oir River to assist in determining the week(s) in which turbines have to be shut down. Using a detection threshold of $10 \%$ of the mean annual number of migrants in this river during the prediction period (i.e. 5 individuals), the FMM model 
detected 360 of the 396 silver eels enumerated during this period. With this decision criterion, $90 \%$ of migrant silver eels in the Oir River would have been saved, requiring an average of 5.6 turbine shutdowns per year (Fig. 3, grey bars). Using a $20 \%$ threshold of the mean annual number of migrants (10 eels) would have saved $77.5 \%$ of migrant eels with 3.8 shutdowns per year.

Similarly, FMM was also used as a management tool on the Scorff River. Using a protocol of turbine shutdowns when forecasting exceeded $10 \%$ of the mean annual number of migrants (i.e. 3 eels) would

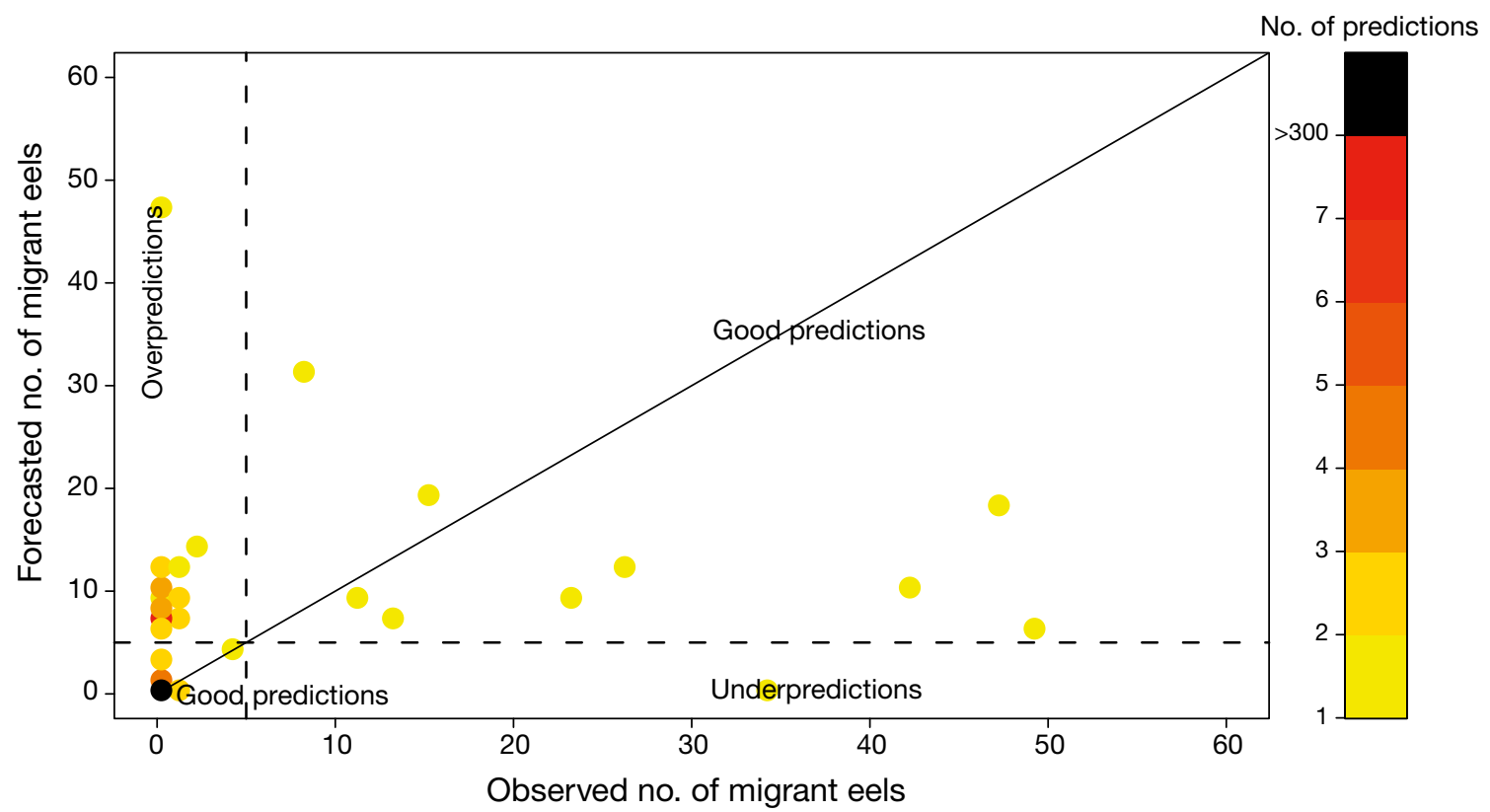

Fig. 5. Evaluation of the forecasting migration model on the Oir River using a threshold of $10 \%$ of the mean annual number of migrants ( $=5$ eels in this system) (dashed lines) for the 364 wk studied. $x$-coordinates are observed weekly migrants; $y$-coordinates are forecasted weekly migrants. The colours of the circles is a function of the number of points with the same coordinates: Of ca. $340 \mathrm{wk}$ of predictions, $>300 \mathrm{wk}$ corresponded to 0 predicted and 0 observed eels

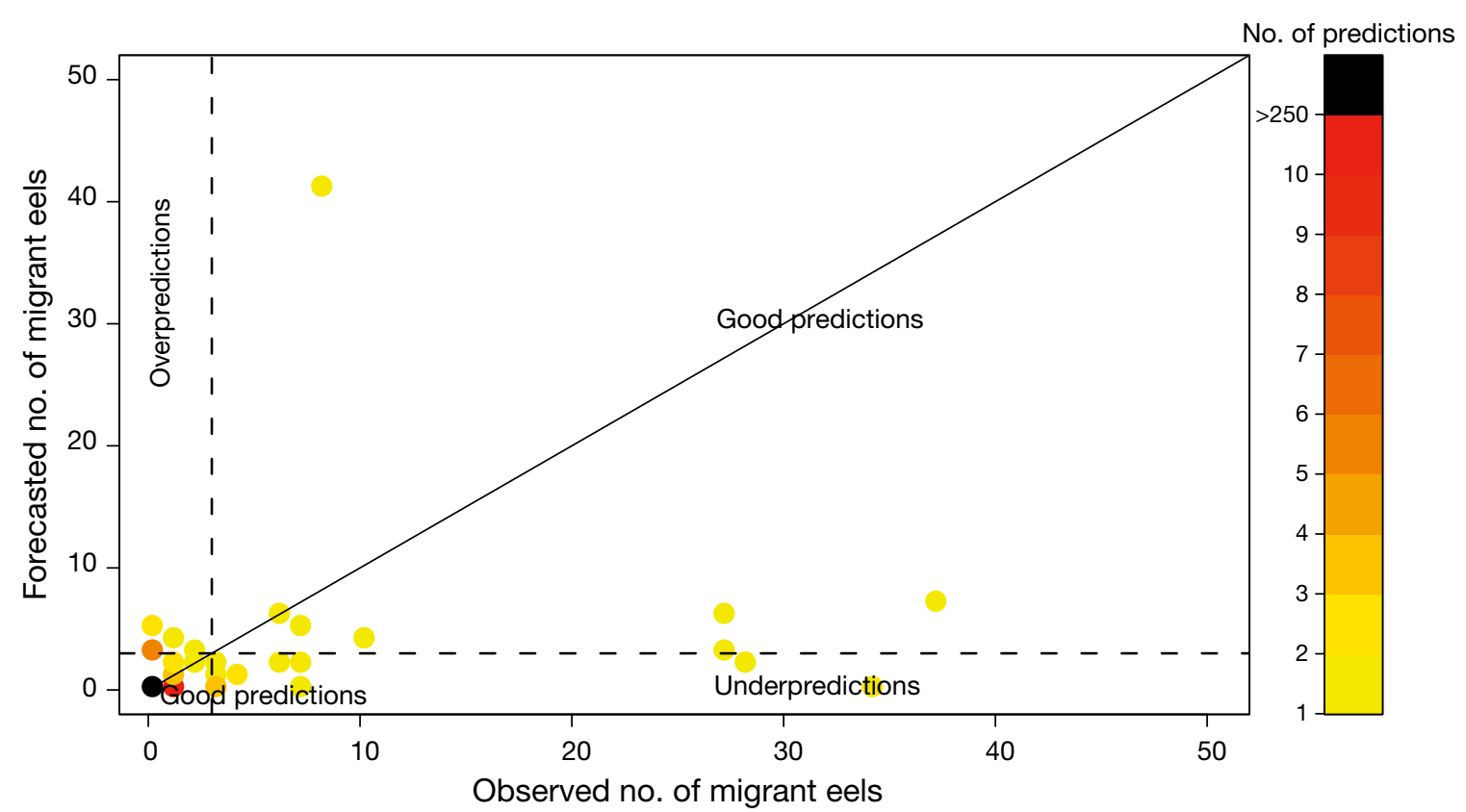

Fig. 6. Evaluation of the forecasting migration model on the Scorff River using a threshold of $10 \%$ of the mean annual number of migrants ( $=3$ eels in this system) (dashed lines) for the 312 wk studied. $x$-coordinates are observed weekly migrants; $y$-coordinates are forecasted weekly migrants. The colour of the circles is a function of the number of points with the same coordinates: Of ca. 340 wk of predictions, $>250$ wk corresponded to 0 predicted and 0 observed eels 


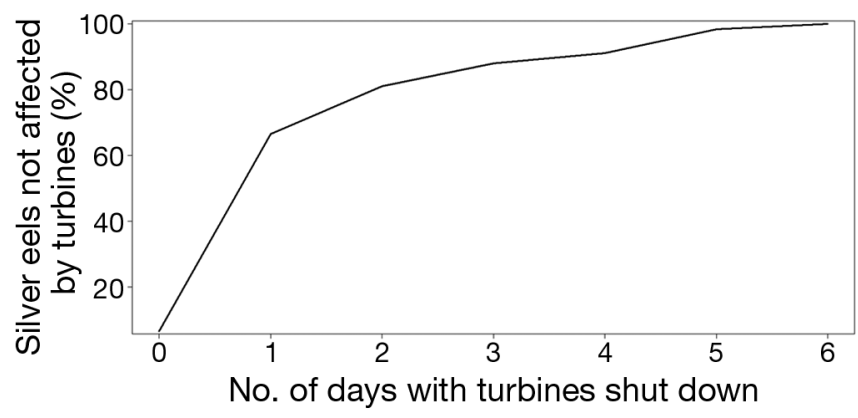

Fig. 7. Effect of an increase in the number of days turbines are shut down after the maximum weekly rainfall on the percent of silver eels unaffected by turbines

have saved almost $71 \%$ of migrant eels in the Scorff River with 3.3 turbine shutdowns per year (Fig. 4), or $60 \%$ of migrant eels using a threshold of $20 \%$ of the mean annual number of migrants.

With a $10 \%$ mean annual migration threshold in the Oir River, FMM was $92.7 \%$ accurate in predicting that a particular week would have no migration (Table 3, Fig. 5). Only in $7.3 \%$ of the cases did FMM forecast an absence of migration when migration was actually observed (under-prediction). Our model was $91 \%$ accurate in predicting weeks with observed peaks. In terms of the number of individuals (quantitative approach), nearly $90 \%$ of migrant eels would be saved. In only $10 \%$ of predictions did FMM forecast migration, when none was observed (over-prediction).

FMM efficiency on the Scorff River seems to be lower because FMM only correctly predicted $43 \%$ of the weeks with observed migration (Table 3). However, the under-prediction was mainly for very small migrations, $<10$ fish (Fig. 6). Indeed, the $43 \%$ of predictions that were correct accounted for $70 \%$ of the total migrant fish. Finally, the absence of migration was predicted correctly in $>96 \%$ of weeks without observed migration.

\section{Improving the timing: duration of turbine shutdown}

In a further step, this study aimed to improve the accuracy of the timing migration forecast in order to reduce the duration of turbine shutdown. Indeed, because our model uses weekly data, it produces weekly forecasts. FMM recommended that turbines be shut down 3.3 to $5.6 \mathrm{wk} \mathrm{yr}^{-1}$ to reduce mortality in line with the European eel management plan, although it is well known that silver eel runs last for only a few hours within any given week. Thus, we attempted to provide a more precise forecast of the timing of the migration, using the strong link between migration and rainfall. We calculated the number of silver eel migrants $1,2,3,4,5$ and $6 \mathrm{~d}$ after the weekly maximum of rainfall for the Oir River. Our results showed that shutting down the turbines for only the first $2 \mathrm{~d}$ after the maximum rainfall would have led to the survival of $80 \%$ of the silver eels (Fig. 7).

\section{DISCUSSION}

The reduction of exogenous factors used in our model is a crucial point, and we selected models that use only rainfall. In small river systems $(<100$ to ca. $500 \mathrm{~km}^{2}$ ), rainfall appears to be the most pertinent factor because it can be considered as a proxy for almost all exogenous cues affecting migrations: river flow, temperature change, wind, atmospheric pressure, turbidity and luminosity (by the associated cloud cover). The need for only a single exogenous factor makes the model easier for managers to use. Moreover, this factor (rainfall) is easy to measure and to forecast up to a week in advance. Therefore, the model proposed in the present study can be used very easily for effective species management.

Two issues are very important for efficient fish management. First, it is important to forecast when the turbines can be active without the risk of a migration occurring. Using a threshold corresponding to $10 \%$ of the mean annual number of migrants, our model clearly showed that the weeks without migration were very well detected $(92.7 \%$ of cases for the Oir River and 96.5\% of cases for the Scorff River).

From an ecological perspective, the most important issue is to forecast the migration peak. FMM clearly showed that it was possible to forecast major peaks with only 1 simple covariate. Using an FMM model on the Oir and Scorff Rivers would have saved 70 and $90 \%$ of the migrant silver eels, respectively. However, forecasting accuracy needs to be improved, especially in large river systems where more environmental cues are likely to trigger migration.

Our results suggest that the timing of migration can be explained primarily by total weekly rainfall. The quality of forecasting of major peaks (i.e. peaks $>10 \%$ of annual migrants) means that the timing of migration for between 70 and $90 \%$ of silver eels can be forecast. On the other hand, the annual number of migrants is relatively unpredictable. In the FMM model, this number is calculated using SARIMA and past migration data. The high annual variability could explain the observed errors. At the beginning of the migration period, very heavy rainfall will trigger a migration run. If rainfall is very heavy, the whole population of 
silver eels that are ready to migrate will move. However, the size of this population is not related to the intensity of rainfall, but it is dependent on population dynamics parameters (recruitment, mortality) that cannot be modelled in the FMM.

Future forecasting seems to be possible, but only for the timing of the migration. The intensity of migrations has to be forecast both as an informative factor and to detect threshold values in the decision criterion.

As a further step in the analysis, we improved the accuracy of the forecasts to reduce the duration of turbine shutdown. Our results showed that shutting down the turbines only during the first $2 \mathrm{~d}$ after the maximum rainfall would have led to the survival of $80 \%$ of the silver eels (Fig. 7) in the Oir River. The number of days with turbine shutdowns could be significantly reduced without significantly reducing the number of eels saved. With this improvement, the average $3.3 \mathrm{wk}$ yearly shutdowns could be limited to an average of $6.6 \mathrm{~d}$. This method considerably improves the accuracy of the forecast and also leads to a considerable gain for energy producers. Indeed, during high winter flow events, the power production and related income are potentially high and economically important for hydropower producers.

This study showed that, for particular watersheds, it is possible to provide a precise forecast of the timing of silver eel migration. However, this model is limited to small watersheds, where rainfall is the main factor explaining eel migration. We recommend that before using the model in other watersheds the correlation between rainfall and eel migration should be examined. If a positive relationship is found, then it should be possible to use the FMM. For sites without capture data, the question of extrapolation of model parameters has been investigated. Preliminary results suggest that extrapolation (i.e. use of the FMM with model coefficients from another watershed) may be possible, but only with similar watersheds located in the same geographical area, which would likely have the same phenological migration period. In larger rivers, numerous factors are known to rule migration patterns. Rainfall is the most cited factor, but river flow, temperature, lunar phase, wind, atmospheric pressure, turbidity and conductivity (see references in Table 1 for details) have also been cited.

Forecasting migration in larger systems is very complex and has sometimes been considered impossible (Durif \& Elie 2008). This may be due to the number of exogenous factors that are able to trigger or inhibit the migration, and by their interactions. In the final analysis, past biological data appears to be the most important factor for forecasting future biological data, and future models have to integrate this.

Previous models used in migration forecasting were based on exogenous factors. In the actual context of climatic change, we assume that it is not reasonable to depend on the quality of forecasting using only factors that are frequently and strongly modified. For example, if a virtual linear model, such that the number of silver eels is correlated with rainfall, was created from years with 'mean' rainfall, we have shown that this model would produce incorrect forecasts in years with 'non-normal' rainfalls, i.e. floods or droughts. Even during a severe drought, the stock of silver eels is affected several years in advance by population dynamics. Then, during the drought, a very low peak of rainfall could provoke an unexpected downstream migration.

SARIMAX models can reduce the influence of exogenous factors in forecasting outcomes, these being the most variable factors in the actual context of climate change. In our simulations using real data results showed that SARIMAX appears to be an effective tool for explaining migrations, and thus could be useful in forecasting silver eel migrations.

Acknowledgements. The authors sincerely thank Meteo France and J. M. Le Gallic for the meteorological data. We are deeply grateful to F. Travade (EDF) for his support throughout this study through fascinating discussions. We also thank our colleagues at INRA, J. M. Roussel, F. Marchand and R. Delanoé, for eel data acquisition.

\section{LITERATURE CITED}

Acou A, Feunteun E, Laffaille P, Legault A (2000) Catadromous migration dynamics of European eel (Anguilla anguilla, L.) in a dammed catchment. Verh Int Ver Limnol 27:1-4

Acou A, Boury P, Laffaille P, Crivelli AJ, Feunteun E (2005) Towards a standardized characterization of the potentially migrating silver European eel (Anguilla anguilla, L.). Arch Hydrobiol 164:237-255

Acou A, Laffaille P, Legault A, Feunteun E (2008) Migration pattern of silver eel (Anguilla anguilla, L.) in an obstructed river system. Ecol Freshw Fish 17:432-442

Acou A, Rivot E, van Gils JA, Legault A, Ysnel F, Feunteun E (2011) Habitat carrying capacity is reached for the European eel in a small coastal catchment: evidence and implications for managing eel stocks. Freshw Biol 56: 952-968

Adamczewska AM, Morris S (2001) Ecology and behavior of Gecarcoidea natalis, the Christmas Island red crab, during the annual breeding migration. Biol Bull 200:305-320

Allen JB, Rabiner LR (1977) Unified approach to short-time Fourier-analysis and synthesis. Proc IEEE 65:1558-1564

Behrmann-Godel J, Eckmann R (2003) A preliminary telemetry study of the migration of silver European eel (Anguilla anguilla L.) in the River Mosel, Germany. Ecol Freshw Fish 12:196-202 
Boubee JA, Mitchell CP, Chisnall BL, West DW, Bowman EJ, Haro A (2001) Factors regulating the downstream migration of mature eels (Anguilla spp.) at Aniwhenua Dam, Bay of Plenty, New Zealand. N Z J Mar Freshw Res 35: 121-134

Bruijs MCM, Hadderingh RH, Schwevers U, Adam B, Dumont U, Winter HV (2009) Managing human impact on downstream migrating European eel Anguilla anguilla in the River Meuse. Eels at the Edge Conference, Quebec 2009

Burnet AMR (1969) Migrating eels in a Canterbury river, New Zealand. N Z J Mar Freshw Res 3:230-244

Craine MD, Cheng YW, Prescott J (2003) A catch rate-environment time series approach to the prediction of catches taken from the Esperance southern rock lobster fishery. In: MODSIM 2003 International Congress on Modelling and Simulation Location, July 14-17, 2003, Townsville. University of Western Australia, Nedlands, p 1275-1280

Cullen P, McCarthy TK (2003) Hydrometric and meteorological factors affecting the seaward migration of silver eels (Anguilla anguilla, L.) in the lower River Shannon. Environ Biol Fishes 67:349-357

Dingle H (1996) Migration: the biology of life on the move. Oxford University Press, Oxford

$>$ Dowse HB, Ringo JM (1989) The search for hidden periodicities in biological time series revisited. J Theor Biol 139: 487-515

$>$ Durif C, Elie P (2008) Predicting downstream migration of silver eels in a large river catchment based on commercial fishery data. Fish Manag Ecol 15:127-137

Durif C, Elie P, Gosset C, Rives J, Travade F (2003) Behavioral study of downstream migrating eels by radiotelemetry at a small hydroelectric power plant. In: Dixon DA (ed) Biology, management, and protection of catadromous eels. American Fisheries Society Symposium, Bethesda, MD, p 343-356

> Durif C, Dufour S, Elie P (2005) The silvering process of Anguilla anguilla: a new classification from the yellow resident to the silver migrating stage. J Fish Biol 66: 1026-1043

> Geremia C, White PJ, Wallen RL, Watson FGR and others (2011) Predicting bison migration out of Yellowstone National Park using Bayesian models. PLoS ONE 6: e16848

Gosset C, Travade F, Durif C, Rives J, Elie P (2005) Test of two types of bypass for downstream migration of eels at a small hydroelectric power plant. River Res Appl 21: 1095-1105

Hadderingh RH, Van Aerssen GHFM, De Beijer RFLJ, Van der Velde G (1999) Reaction of silver eels to artificial light sources and water currents: an experimental deflection study. Regul Rivers Res Manag 15:365-371

Haraldstad O, Vollestad LA, Jonsson B (1985) Descent of European silver eels, Anguilla anguilla L., in a Norwegian watercourse. J Fish Biol 26:37-41

Haro A (2003) Downstream migration of silver-phase anguillid eels. In: Aida K, Tsukamoto K, Yamauchi K (eds) Eel biology. Springer, Tokyo, p 215-222

Haro A, Castro-Santos T, Whalen K, Wippelhauser G, Mclaughlin L (2003) Simulated effects of hydroelectric project regulation on mortality of American eels. In: Dixon DA (ed) Biology, management, and protection of catdromous eels. American Fisheries Society, Bethesda, MD, p 357-365
Hecker GE, Cook TC (2005) Development and evaluation of a new helical fish-friendly hydroturbine. J Hydraul Eng 131:835-844

> Klueken AM, Hau B, Ulber B, Poehling HM (2009) Forecasting migration of cereal aphids (Hemiptera: Aphididae) in autumn and spring. J Appl Entomol 133:328-344

Larinier M, Travade F (2002) Downstream migration: problems and facilities. Bull Fr Peche Piscicult 364 (Suppl): 181-207

> Lowe RH (1952) The influence of light and other factors on the seaward migration of the silver eel (Anguilla anguilla L.). J Anim Ecol 21:275-309

> McCarthy TK, Frankiewicz P, Cullen P, Blaszkowski M, O'Connor W, Doherty D (2008) Long-term effects of hydropower installations and associated river regulation on River Shannon eel populations: mitigation and management. Hydrobiologia 609:109-124

McDowall RM (1988) Diadromy in fishes: migration between freshwater and marine environments. Croom Helm, London

Mills TC (1990) Time series techniques for economists. Cambridge University Press, Cambridge

> Miyai T, Aoyama J, Sasai S, Inoue JG, Miller MJ, Tsukamoto $\mathrm{K}$ (2004) Ecological aspects of the downstream migration of introduced European eels in the Uono River, Japan. Environ Biol Fishes 71:105-114

Moriarty C (1989) The silver eel catch on the lower River Shannon, Ireland. EIFAC Working Party on Eel, Porto, p 1-11

Nyquist H (1928) Certain topics in telegraph transmission theory, winter convention of the A.I.E.E. In: Transactions of the A.I.E.E. A.I.E.E., New York, NY, p 617-644

> Okamura A, Yamada Y, Mikawa N, Tanaka S, Oka HP (2002) Exotic silver eels Anguilla anguilla in Japanese waters: seaward migration and environmental factors. Aquat Living Resour 15:335-341

Poole WR, Reynolds JD (1990) Observations on the silver eel runs of the Burrishoole River System, Ireland, 1959 to 1988. Int Rev Gesamten Hydrobiol Hydrograph 75: 807-815

Russon IJ, Kemp PS, Calles O (2010) Response of downstream migrating adult European eels (Anguilla anguilla) to bar racks under experimental conditions. Ecol Freshw Fish 19:197-205

Tankersley CD, Graham WD, Hatfield K (1993) Comparison of univariate and transfer function models of groundwater fluctuations. Water Resour Res 29:3517-3533

- Todd PR (1981) Timing and periodicity of migrating New Zealand freshwater eels (Anguilla spp.). NZ J Mar Freshw Res 15:225-235

> Van Belle J, Shamoun-Baranes J, Van Loon E, Bouten W (2007) An operational model predicting autumn bird migration intensities for flight safety. J Appl Ecol 44: 864-874

> Vollestad LA, Jonsson B, Hvidsten NA, Naesje TF, Haraldstad O, Ruud-Hansen J (1986) Environmental factors regulating the seaward migration of European silver eels (Anguilla anguilla). Can J Fish Aquat Sci 43:1909-1916

Watene EM, Boubee JAT (2005) Selective opening of hydroelectric dam spillway gates for downstream migrant eels in New Zealand. Fish Manag Ecol 12:69-75

Zhu LX, Li LF, Liang ZL (2009) Comparison of six statistical approaches in the selection of appropriate fish growth models. Chin J Oceanol Limnol 27:457-467 